\title{
Changes in the Properties of Porcine Myosin during Postmortem Aging
}

\author{
Hala Ahmed Abdel-Mohsen, ${ }^{1}$ Mitsutoshi NaKamoto, ${ }^{1}$ Jim-Bo Kim, ${ }^{2}$ Yoshihito Nogusa, ${ }^{3}$ Kunihiko GeKKo, ${ }^{3}$ \\ Makoto IsHIOROSHI, ${ }^{2}$ Kunihiko SAMEJIMA, ${ }^{2}$ Soichi TANABE ${ }^{1}$ and Toshihide NISHIMURA ${ }^{1 *}$ \\ ${ }^{1}$ Graduate School of Biosphere Science, ${ }^{3}$ Graduate School of Science, Hiroshima University, Higashihiroshima 739-8528, Japan \\ ${ }^{2}$ Faculty of Dairy Science, Rakuno Gakuen University , Ebetsu, Hokkaido 069-8501, Japan
}

Received March 10, 2003; Accepted June 11, 2003

\begin{abstract}
Physicochemical and conformational changes, water-holding capacity (WHC) and the structure of heat-induced gel of porcine myosin were investigated to elucidate the relationship between denaturation of myosin and gelation properties during postmortem aging. The turbidity of porcine myosin upon heating increased as the period of postmortem aging increased. During postmortem aging, the increased velocity in values of aliphatic hydrophobicity of porcine myosin by heating was prominent, which suggested that porcine head was susceptible to conformational changes during storage. On the other hand, according to the changes in circular dichroism (CD) spectra of heated porcine myosin, the decrease in $\alpha$-helix content was almost the same during postmortem aging, indicating no conformational changes in porcine myosin rod during aging. WHC values of porcine myosin gels showed a gradual decrease during storage. This coincided with the progressive loosening in its three dimensional ordering with increased postmortem aging period, as was revealed by SEM studies. In conclusion, conformational changes of myosin head by denaturation during postmortem aging of pork could cause a progressive loosening of heat-induced gel of porcine myosin. This result could be, in part, helpful in the subsequent use of pork in meat processing.
\end{abstract}

Keywords: myosin (porcine), physicochemical changes, myosin subfragments (head, rod), conformational changes, postmortem aging, scanning electron microscope, gel matrix

The gel forming ability of myofibrillar proteins is important for many processes involved in the production of a variety of products made from meat such as sausages. This and other functional properties determine the textural qualities and physical behavior of meat products during preparation, processing and storage, as well as stabilizing fat and water-holding capacity (Schmidt, 1981; Morrissey et al., 1987; Cofrades et al., 1997). The formation of a protein network in these products contributes not only to the elastic texture, but also to other functional properties that are important in stimulating the appearance, flavor and palatability of the material meats (Park et al., 1997). For example, palatability of pork sausages is known to be better than that of beef ones, which could probably be due to species-specific properties of network or gel formation.

The ability to form gel upon heating has been shown to be brought about mainly by myosin. It was also shown that other myofibrillar proteins such as actin cannot in themselves form a gel upon heating but modify the gelling characteristics of myosin gel (Yasui et al., 1980; Visessanguan et al., 2000). Since the pioneering findings on myosin binding ability to adhere meat pieces together by gelation through thermal processing (Fukazawa et al., 1961), many studies have been performed. These studies investigated the properties of myosin as the main gelling protein of the muscle and characterized the mechanism of gelation over the past 30 years (Samejima et al., 1969; Macferlane et al., 1977;

\footnotetext{
*To whom correspondence should be addressed.

E-mail: toshixy@hiroshima-u.ac.jp

Abbreviations: CD: circular dichroism, cPA: cis-parinaric acid, DW: distilled water, DTT: dithiothreitol, EDTA: ethylenediamine tetracetate, SDS-PAGE: sodium dodecyl sulphate-polyacrylamide gel, SEM: scanning electron microscopy, WHC: water-holding capacity.
}

Ishioroshi et al., 1979; Acton \& Dick, 1989; Ziegler \& Foegeding, 1990; Liu \& Foegeding, 1996; Visessanguan et al., 2000).

Myosin is a multi-domain protein with two large heavy chains and four light chains arranged into an asymmetrical molecule with two globular heads attached to a long $\alpha$-helical rod-like tail (Privalov, 1982; Lopez-Lacomba et al., 1989; Visessanguan \& An, 2000). ATP- and actin-binding sites are located on the heads, whereas filament-forming ability and the property that myosin dissolves in high-salt medium relies on the rod portion (Harrington, 1979; Wang \& Smith, 1994; Konno et al., 2000). Both head and rod portions of myosin have been shown to participate in gel formation (Taguchi et al., 1987; Chan et al., 1993).

Heat-induced gelation is a complex physicochemical process involving structural and functional changes of myosin. It is represented by three stages, that is, dissociation, thermal denaturation and aggregation (Roussel \& Cheftel, 1990). In the presence of salts, myosin undergoes major structural and conformational changes leading to solubilization of myosin and actin (Parsons \& Knight, 1990). Partial unfolding of the protein structure is accelerated by an increase in temperature, which results in the aggregation of the unfolded regions between protein molecules to form a three-dimensional network (Visessanguan et al., 2000). The structural and conformational changes that occur in the head and rod portions as a result of thermal denaturation enable myosin to form gel. It is also well known that the gelling properties of myosin are highly related to species, conditions of myosin preparations and postmortem aging period as well.

In Japan meats, stored at $4^{\circ} \mathrm{C}$ for several days and imported under vacuum-packing from foreign countries, are used for making meat products such as sausages (Okumura et al., 1996). The 
aging period of meat differs from one type of meat to another; while beef is stored from 2-4 weeks, pork is stored for only about 6-10 days (Takahashi, 1999). During this postmortem aging, various changes occur in muscle proteins even at low temperature. Many studies investigated the physiological and biochemical changes during postmortem aging (Alarcon-Rojo \& Dransfield, 1995; Steen et al., 1997; Nishimura, 1998). On the other hand, few studies referred to the effect of postmortem storage on the physicochemical changes of porcine myosin, its gelling process or its water binding properties. In this study, we examined the physicochemical and conformational changes, water-holding capacity of porcine myosin and observed the structure of its heat-induced gel to elucidate the relationship between denaturation of myosin and gelation properties during postmortem aging.

\section{Materials and Methods}

Meat samples Porcine muscles (M. longissimus dorsi) were supplied by Nippon Meat Packers Company, and transferred to our laboratory two days after slaughter. Meat was then stored at $4^{\circ} \mathrm{C}$. Myosin was successively extracted from porcine meat 3,5, 7, and 9 days after slaughter.

Myosin extraction Myosin was extracted from porcine meat by "Hasselbach-Schneider" buffer $(0.6 \mathrm{M} \mathrm{KCl} / 10 \mathrm{mM}$ $\mathrm{MgCl}_{2} / 200 \mathrm{~mm} \mathrm{~K}$-phosphate/20 mM pyrophosphoric acid) (Hasselbach \& Schneider, 1951). In each extraction, $200 \mathrm{~g}$ of minced meat was used, to which $600 \mathrm{ml}$ of the extraction buffer was added. Extraction was done within $15 \mathrm{~min}$ by slow and continuous stirring with occasional pauses and was then stopped by the addition of $800 \mathrm{ml}$ of cold distilled water (DW). The mixture was centrifuged at $3000 \times g$ for $10 \mathrm{~min}$, and the muscle residue was separated by filtration through four layers of gauze. To get myo$\sin$ as a precipitate, the filtrate was diluted with an equal volume of cold DW, and then centrifuged at $10,000 \times g$ for $15 \mathrm{~min}$. Myosin pellets were suspended in $0.12 \mathrm{M} \mathrm{KCl} / 20 \mathrm{mM} \mathrm{K}$-phosphate (pH 7.2)/1 mM ethylenediamine tetracetate (EDTA)/1 mM dithiothreitol (DTT) and then washed twice with the same buffer. During the whole period of experiments, myosin solution was kept at $4^{\circ} \mathrm{C}$.

Protein concentration Myosin concentration was measured by the method mentioned by Bradford (1976) using a commercial kit (Bio-Rad, Japan). Colored products were measured at $595 \mathrm{~nm}$ on a spectrophotometer (Jasco V-530 UV/Vis, Japan).

Sodium dodecyl sulphate-polyacrylamide gel (SDS-PAGE) measurements Electrophoresis on polyacrylamide gels $(7.5 \%)$ was carried out according to the method mentioned by Laemmli (1970). Porcine myosin was dissolved with $10 \mathrm{mM}$ Tris- $\mathrm{HCl}$ buffer (pH 6.8), containing 1\% SDS, 1\% 2-mercaptoethanol and $20 \%$ glycerol. The solution was then boiled for $2 \mathrm{~min}$ before being applied to the gel. Electrophoresis was carried out and the resulting gel was stained with Coomassie brilliant blue. The density of each band was measured by a densitometer (Toyo, DMU33C, Japan).

Turbidity Myosin $(1 \mathrm{mg} / \mathrm{ml})$ was dissolved in $0.6 \mathrm{M} \mathrm{KCl}$ / $50 \mathrm{mM}$ K-phosphate buffer (pH 6.5). The absorbance was monitored during heating of the porcine myosin solution from 30 to $80^{\circ} \mathrm{C}$ at an increasing rate of $3^{\circ} \mathrm{C} / \mathrm{min}$ using a spectrophotometer (Shimadzu UV-250, Japan) at $340 \mathrm{~nm}$.

Hydrophobicity Hydrophobicity was measured according

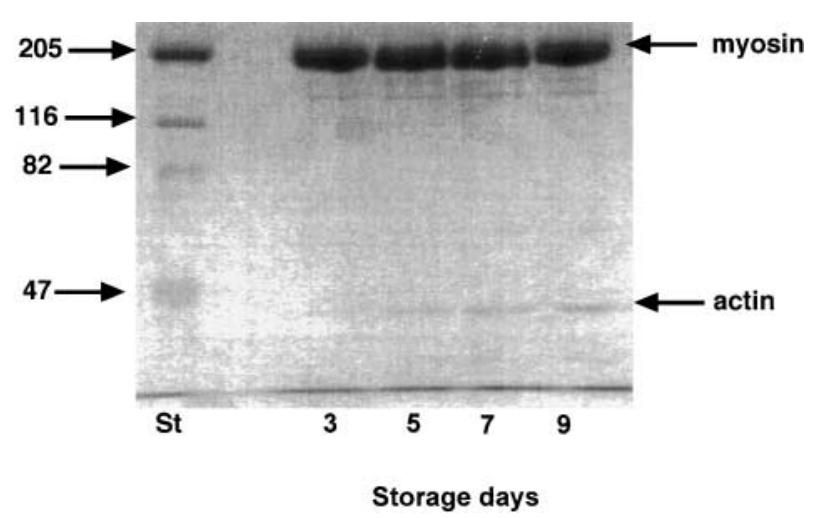

Fig. 1. SDS-PAGE of myosin isolated from porcine muscles. Myosin was isolated with Hasselbach-Schneider buffer from porcine muscles, stored at $4^{\circ} \mathrm{C}$, and was extracted on the $3,5,7$ and 9 days after slaughter. Acrylamide concentration of the separating gel was $7.5 \%$.

to the method mentioned by Boyer et al. (1996). Three milliliters of porcine myosin $(0.04 \mathrm{mg} / \mathrm{ml})$ in $0.6 \mathrm{M} \mathrm{KCl} / 50 \mathrm{mM} \mathrm{K}$-phosphate buffer ( $\mathrm{pH} 6.5$ ) was heated for $5 \mathrm{~min}$ at each temperature from 30 to $80^{\circ} \mathrm{C}$ and, after heating, cooled on ice. Ten microliters of $1 \mathrm{mM}$ cis-parinaric acid solution (cPA) was then added to each solution. The fluorescence of cPA protein complex was measured with a spectrofluorometer (Jasco FP-750, Japan). Hydrophobicity was expressed as $\mu \mathrm{M}^{-1}$ of myosin $\mu \mathrm{M}^{-1}$ of cPA.

ATPase activity ATPase activity measurements were carried out at $25^{\circ} \mathrm{C}$ by the method of Maruyama and Ishikawa (1963). Myosin solution $(0.25 \mathrm{mg} / \mathrm{ml})$ was incubated with $1 \mathrm{mM}$ ATP, $2 \mathrm{mM} \mathrm{MgCl}_{2}, 50 \mathrm{mM} \mathrm{KCl}, 2 \mathrm{mM} \mathrm{NaN}_{3}$ in $20 \mathrm{mM}$ Tris- $\mathrm{HCl}$ buffer ( $\mathrm{pH} 8$ ) for $10 \mathrm{~min}$. ATPase activity was expressed as $\mu \mathrm{g}$ phosphorus liberated for $1 \mathrm{~min}$ by $1 \mathrm{mg}$ of protein.

$\alpha$-Helix measurements Myosin $(0.05 \mathrm{mg} / \mathrm{ml})$ was dissolved in $0.6 \mathrm{M} \mathrm{KCl} / 50 \mathrm{mM} \mathrm{K}$-phosphate buffer (pH 6.5). The solution was then heated gradually from 15 to $75^{\circ} \mathrm{C}$. The $\alpha$-helix content of myosin was calculated based on a CD spectrum (Jasco $\mathrm{J}-720 \mathrm{~W}$ ). The molar ellipticity [ $\theta]$ at $222 \mathrm{~nm}$ was monitored during heating.

Water-holding capacity (WHC) measurements WHC was performed according to the method mentioned by Smyth et al. (1998). Briefly, porcine myosin $(10 \mathrm{mg} / \mathrm{ml})$ in $0.6 \mathrm{M} \mathrm{KCl}$ buffer (pH 6.5) was heated from 20 to $90^{\circ} \mathrm{C}$ at a rate of $1.75^{\circ} \mathrm{C} / \mathrm{min}$. The gels were transferred to a cold room $\left(4^{\circ} \mathrm{C}\right)$ and held for $12 \mathrm{~h}$. Gels of known weight $\left(W_{1}\right)$ were centrifuged at $800 \times \mathrm{g}$ for $15 \mathrm{~min}$ at $4^{\circ} \mathrm{C}$. The weight of the resulting supernatant $\left(W_{2}\right)$ was recorded. WHC was calculated as follows:

$$
\mathrm{WHC}=\left(W_{1}-W_{2}\right) / W_{1} \times 100 .
$$

Scanning electron microscope (SEM) Porcine myosin gel samples were prepared for SEM observation adopting the method mentioned by Yasui et al. (1979). In this method, protein solutions $(10 \mathrm{mg} / \mathrm{ml})$ of myosin in $0.6 \mathrm{M} \mathrm{KCl}$ and $20 \mathrm{~mm} \mathrm{~K}$-phosphate buffer (pH 6.0) were incubated at $60^{\circ} \mathrm{C}$ for $30 \mathrm{~min}$. Gel pieces less than $1 \mathrm{~mm}^{3}$ were immersed in $2.5 \%$ glutaraldehyde in $0.1 \mathrm{M} \mathrm{K}$-phosphate buffer ( $\mathrm{pH} 7.0$ ) for $2 \mathrm{~h}$ at $4^{\circ} \mathrm{C}$. All fixed specimens were dipped in distilled water and dehydrated in graded ethanol of $30,50,70,90,95$, and $100 \%$ for at least $15 \mathrm{~min}$ per station. After dehydration, they were transferred to 50 and $100 \%$ isoamylacetate for $30 \mathrm{~min}$ each. Samples were dried by a carbon 


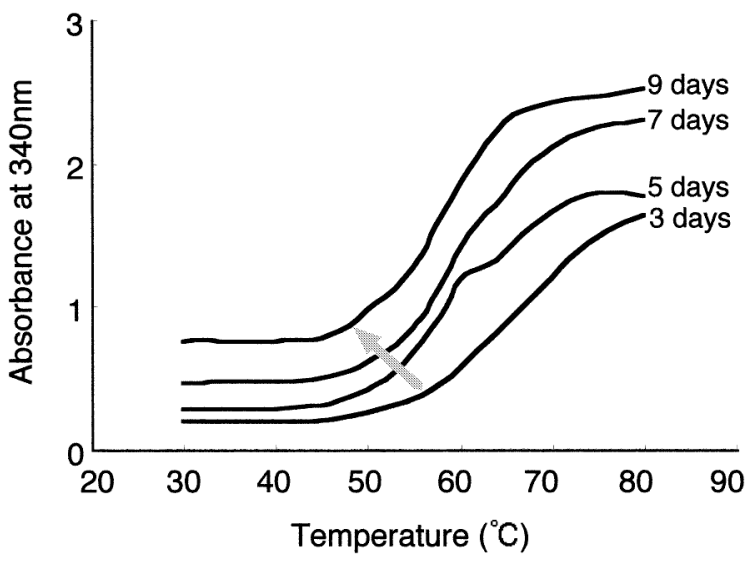

Fig. 2. Changes in turbidity at $340 \mathrm{~nm}$ of porcine myosin during storage. Myosin $(1 \mathrm{mg} / \mathrm{ml})$ was dissolved with $0.6 \mathrm{M} \mathrm{KCl} / 50 \mathrm{~mm} \mathrm{~K}$-phosphate buffer (pH 6.5) and then heated from 30 to $80^{\circ} \mathrm{C}$ at a rate of $3^{\circ} \mathrm{C} / \mathrm{min}$. The arrow in the Figure indicates that the temperature, at which the absorbance of porcine myosin solution started to increase steeply, became lower as the aging period increased.

dioxide critical point dryer (Hitachi HCP-2, Japan). After the dried specimens were mounted on brass studs and coated with a thin layer of platinum in an Ion Sputter (Hitachi E-1010), they were observed with a scanning electron microscope (Hitachi S$2380 \mathrm{~N}$ ) at an accelerating voltage of $15 \mathrm{KV}$.

\section{Results and Discussion}

Myosin preparation Figure 1 shows the SDS-PAGE profiles of porcine myosin, which was extracted on days 3, 5, 7, and 9 of storage, respectively. The myosin obtained was almost pure except for minor contamination with actin, which increased successively during the postmortem aging period. Based on the densities of their bands, the myosin : actin ratio was estimated to be $70: 1$.

Myosin molecule is composed of a coiled coil rod and two globular heads. The heads are responsible for the hydrolysis of ATP into ADP and phosphorus with the liberation of energy necessary for muscle contraction (Goody et al., 1977). During postmortem aging it is stated that, as long as the endogenous ATP is present, actin and myosin filaments are separated and the muscle remains extensible. However, once ATP has been entirely consumed after death, actin and myosin filaments combine with each other to form actomyosin and the muscle becomes rigid. This rigor mortis represents an irreversible contraction and usually occurs within the first $24 \mathrm{~h}$ after death (Yang et al., 1970). This seems to be why myosin solution, on different days of storage, contained different amounts of actin contamination.

The effect of postmortem aging on the increase of turbidity of porcine myosin upon heating An increase in absorbance (or optical density) of heated myosin solution, results from the formation of myosin aggregates or associations (Morita et al., 1987). In this study, the absorbance of myosin solution was measured at $340 \mathrm{~nm}$ to detect small or fine protein aggregations. The patterns of turbidity changes upon heating, in all myosin solutions from pork stored for 3-9 days after slaughter, showed a gradual increase in values as the period of postmortem aging increased (Fig. 2). Of interest was that the temperature, at which the absorbance of porcine myosin solution started to increase steeply, became lower as the aging period increased as shown by an arrow in Fig. 2. This might indicate that during storage porcine myosin gradually lost its stability. Our results are in agreement with Egelandsdal and Martinsen (1994) who reported an increase in turbidity values of red and white bovine muscles during storage.

The effect of postmortem aging on hydrophobicity of porcine myosin upon heating Hydrophobicity measurements of porcine myosin solution were used in this study to signify the conformational changes which occurred in the myosin globular heads, since most of the hydrophobic bonds are known to be buried in the head subfragment (Boyer et al., 1996). According to Sklar et al. (1977), fluorescent cis-parinaric acid (cPA) probes bind to the aliphatic hydrophobic residues of protein.

Among different days of postmortem aging of porcine myosin, it was shown that, as the period of postmortem aging increased, the aliphatic hydrophobicity displayed by porcine myosin increased upon heating (Fig. 3).

Hydrophobicity is known to contribute largely to the stability and structural conformation of proteins, i.e., the greater surface hydrophobicity results in reduced protein stability (Niwa et al., 1989). By applying this to the present study it could be suggested that porcine myosin head gradually lost its stability as the number of exposed hydrophobic bonds increased during aging.

It is well known that, at high temperatures, the unfolding of myosin molecules leads to the exposure at their surfaces of hydrophobic residues that have been initially buried inside in an intact form. In the present study, there was a gradual increase in the hydrophobicity values between 40 and $65^{\circ} \mathrm{C}$ upon heating the porcine myosin solution followed by a constancy in the values. This increase in hydrophobicity could be attributed to the conformational changes that took place in the head subfragment during heating, and to the release of myosin light chains, preferentially LC1 and LC3 (Sharp \& Offer, 1992; Boyer et al., 1996).

The effect of postmortem aging on ATPase activity of porcine myosin The changes in ATPase activity during postmortem aging of porcine myosin were measured as shown in Fig. 4,

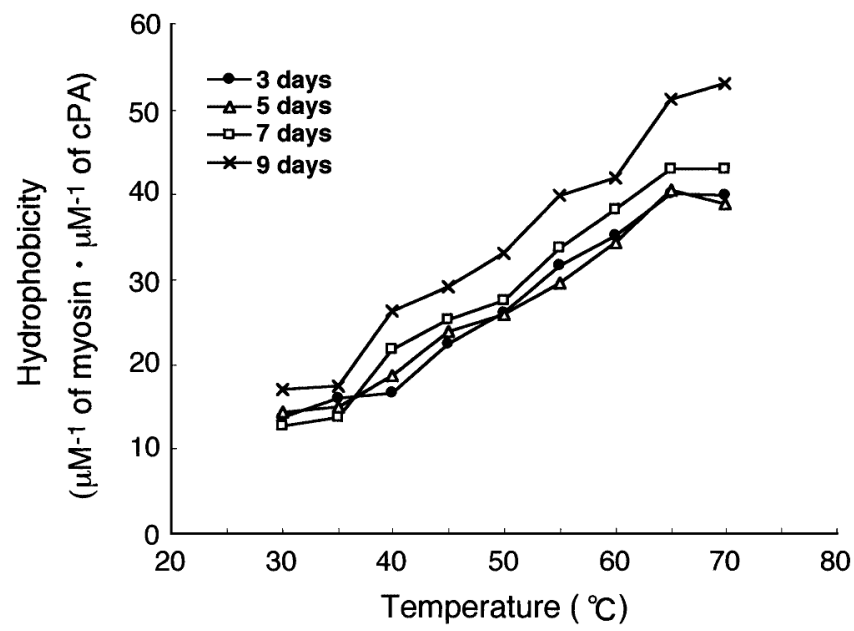

Fig. 3. Changes in aliphatic hydrophobicity of porcine myosin during storage. Myosin $(0.04 \mathrm{mg} / \mathrm{ml})$ was dissolved with $0.6 \mathrm{M} \mathrm{KCl} / 50 \mathrm{~mm} \mathrm{~K}$-phosphate buffer $\left(\mathrm{pH} \mathrm{6.5)}\right.$ ) and then heated from 30 to $80^{\circ} \mathrm{C}$ for $5 \mathrm{~min}$ at each temperature. Hydrophobicity was expressed as $\mu \mathrm{M}^{-1}$ of myosin $\mu \mathrm{M}^{-1}$ of cPA. 
for the purpose of determining the extent of denaturation of head subfragment, since it contains the sites for the hydrolysis of ATP. ATPase activity of porcine myosin showed a slight gradual increase in values during the successive days of storage, which agreed with the results reported by Yang et al. (1970) who observed an increase in ATPase activity of myofibrils from rabbit muscle with the progress of aging.

The increase in ATPase activity values during storage could be accounted for by the increase in actin contamination, which coincidentally increased during storage of porcine myosin (Fig. 1). Fujimaki et al. (1965) examined the effect of actin addition on the ATPase activity of myosin. It was shown that ATPase activity of myosin increased as the binding ratio of F-actin to myosin became higher. The myosin showed the highest activity when the binding ratio of $\mathrm{F}$-actin to myosin was $0.26: 1$. The binding ratio of F-actin to myosin prepared from muscle 9 days after slaughter in this study was $0.14: 1$. This value was located between the minimum and the maximum ratio of F-actin to myosin in the report by Fujimaki et al. (1965). Taken together, the increase in ATPase activity of myosin from stored muscle in the present study seems to have been caused by the increase in actin contamination.

It is worth noting that, contrary to our prior prediction, ATPase activity showed an increase during postmortem aging, while turbidity and hydrophobicity values increased as an indication of protein denaturation. This apparent discrepancy could be explained by the fact that changes in turbidity and hydrophobicity values were measured upon heating porcine myosin, thus causing direct and rapid denaturation of protein. Conversely, ATPase activity was measured at a fixed temperature without applying heat. In other words, ATP hydrolyzing sites located on the head were apparently kept intact during the measuring process.

The effect of postmortem aging on $\alpha$-helix content of porcine myosin upon heating It is well known that the $\alpha$-helix content of myosin rod is over 90\% (Lowey et al., 1969) and that changes in $\alpha$-helix content of porcine myosin by heating were, therefore, mainly due to the conformational changes occurring in the rod during storage.

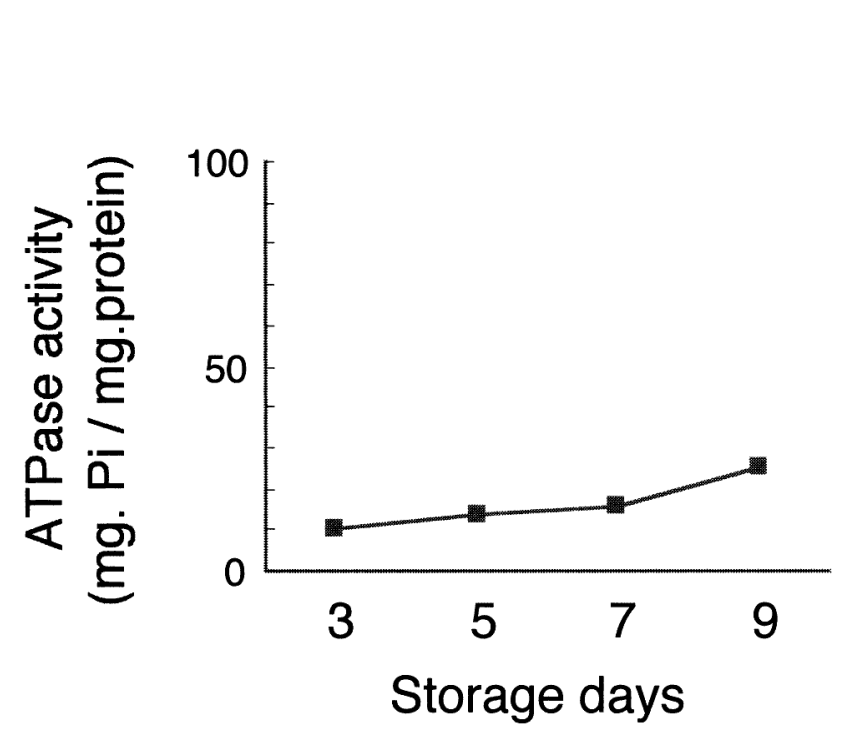

Fig. 4. Changes in ATPase activities of porcine myosin during storage. Myosin solution $(0.25 \mathrm{mg} / \mathrm{ml})$ was incubated with $1 \mathrm{~mm}$ ATP in $20 \mathrm{~mm}$ Tris$\mathrm{HCl}$ buffer $(\mathrm{pH} 8)$ at $25^{\circ} \mathrm{C}$ for $10 \mathrm{~min}$. ATPase activity was expressed as $\mu \mathrm{g}$ phosphorus (Pi) liberated in $1 \mathrm{~min}$ by $1 \mathrm{mg}$ of protein.

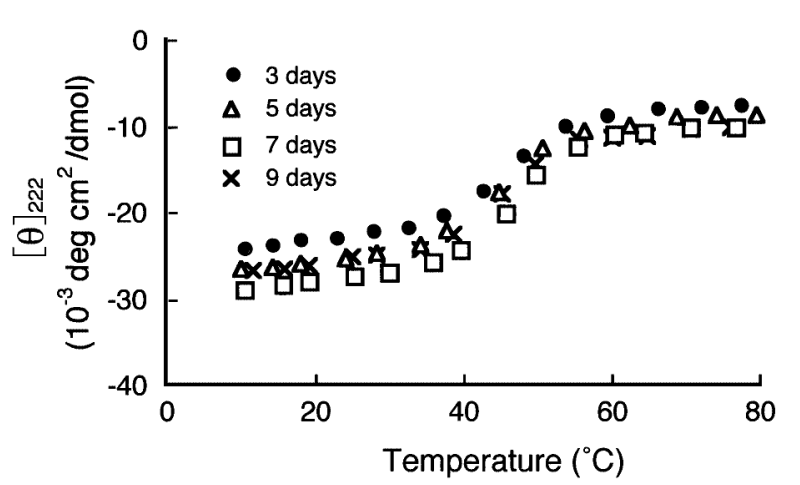

Fig. 5. Changes in $[\theta]_{222}$ of porcine myosin during storage. Myosin $(0.05$ $\mathrm{mg} / \mathrm{ml}$ ) was dissolved with $0.6 \mathrm{M} \mathrm{KCl} / 50 \mathrm{~mm} \mathrm{~K}$-phosphate buffer ( $\mathrm{pH} 6.5$ ) and then heated from 15 to $75^{\circ} \mathrm{C}$. The molar ellipticity [ $\left.\theta\right]$ at $222 \mathrm{~nm}$ was monitored during heating.

$\mathrm{CD}$ analysis is generally performed to detect the changes in $\alpha$ helical content of a protein. A decrease of the magnitude of $[\theta]_{222}$ corresponds to the decrease of the $\alpha$-helical content in protein. Changes in the $\alpha$-helix content of porcine myosin are shown in Fig. 5. In the present study, denaturation of $\alpha$-helix of porcine myosin during postmortem aging was almost the same regardless of the aging period. Therefore, it is suggested that no conformational changes took place in porcine myosin rod during postmortem aging.

By heating myosin solution linearly from 15 to $75^{\circ} \mathrm{C}$, porcine myosin showed a decrease in the $\alpha$-helix content derived from myosin rod. This decrease in $\alpha$-helix content was shown between 40 and $55^{\circ} \mathrm{C}$ until it reached a plateau at $60^{\circ} \mathrm{C}$. Harrington (1979) reported that, by heating myosin rod above $37^{\circ} \mathrm{C}$, the coiled-coil $\alpha$-helix structure of the rod progressively melted to a highly flexible coil, which was almost the same temperature at which porcine myosin rods started to melt.

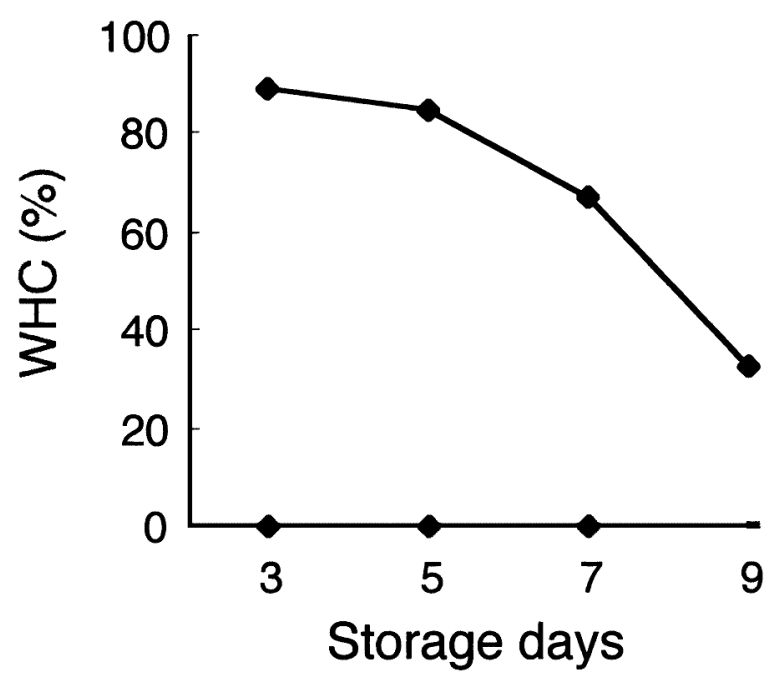

Fig. 6. Changes in water-holding capacity (WHC) values of porcine myosin during storage. Myosin solution $(10 \mathrm{mg} / \mathrm{ml})$ in $0.6 \mathrm{M} \mathrm{KCl}$ buffer $(\mathrm{pH} \mathrm{6.5)}$ was heated from 20 to $90^{\circ} \mathrm{C}$ at a rate of $1.75^{\circ} \mathrm{C} / \mathrm{min}$. Gels of known weight $\left(W_{1}\right)$ were centrifuged at $800 \times g$ for $15 \mathrm{~min}$ at $4^{\circ} \mathrm{C}$, and the weight of the resulting supernatant $\left(W_{2}\right)$ was recorded. WHC was calculated as $\left(W_{1}-W_{2}\right)$ / $W_{1} \times 100$. 
The effect of postmortem aging on water-holding capacity (WHC) of porcine myosin gels WHC is the ability of meat or gel to hold its own or added water during the application of any force such as pressing, grinding, heating and so on (Grau \& Hamm, 1956; Zamorano \& Gambaruto, 1997). In the present study, WHC values of porcine myosin gels extracted on different days of storage were measured. It was found that during storage, WHC values of porcine gels decreased (Fig. 6).

Heat-induced gelation is represented by three stages, that is, dissociation, thermal denaturation and aggregation (Roussel \& Cheftel, 1990). Partial unfolding of the protein structure is accelerated by an increase in temperature resulting in the aggregation of the unfolded regions between protein molecules to form a three-dimensional network matrix (Visessanguan et al., 2000).
The structural and conformational changes that occur in the head and rod portions as a result of thermal denaturation enable myosin to form gel. During postmortem aging, denaturation of myosin took place and the shrinkage of myosin heads occurred, which in consequence resulted in more water being expelled outside the gel matrix by centrifugation. To study the changes in porcine myosin gels during storage, observations by SEM were performed.

Effect of postmortem aging on porcine myosin gel structure Figure 7 illustrates the changes in structure of the heat-induced porcine myosin gels on different days of storage. On the third day of storage, the gels appeared to be dense and of a well-structured matrix with highly interconnected and ordered network strands of uniform thickness (Fig. 7A). Distributed evenly
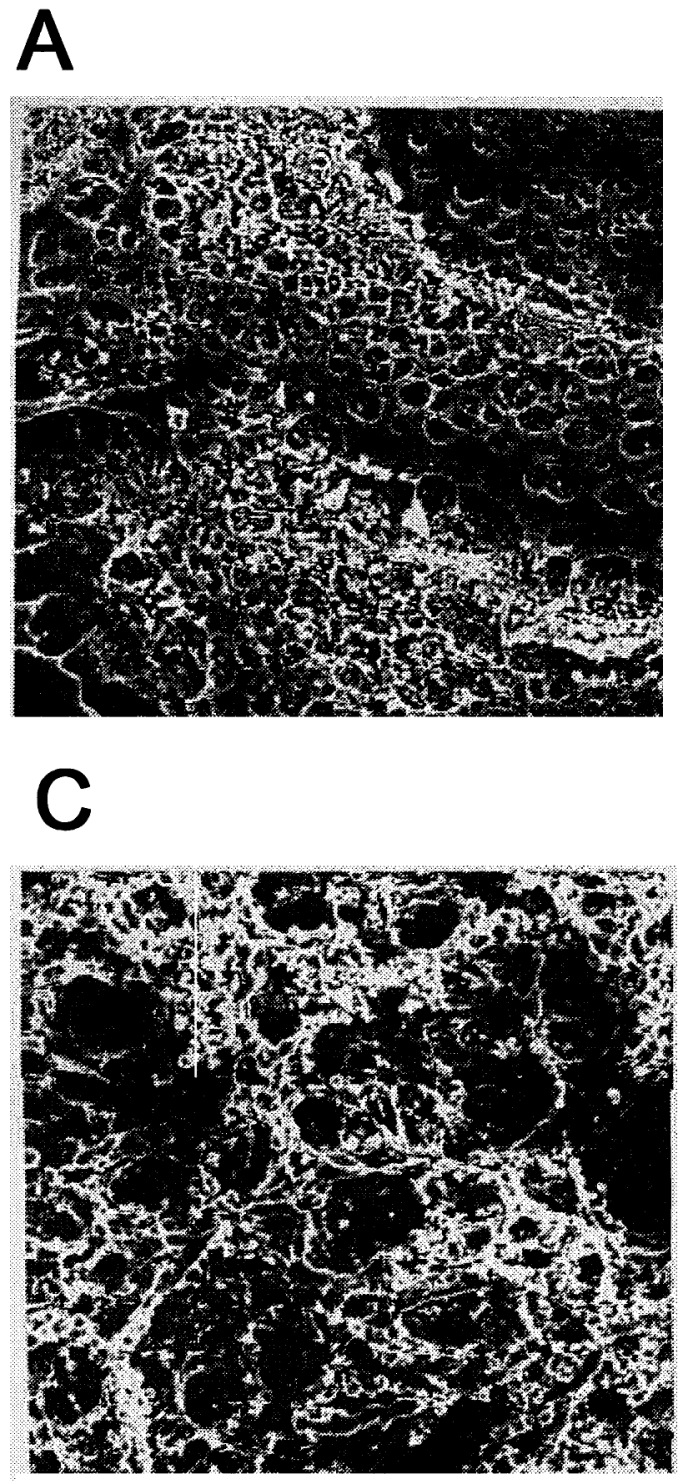
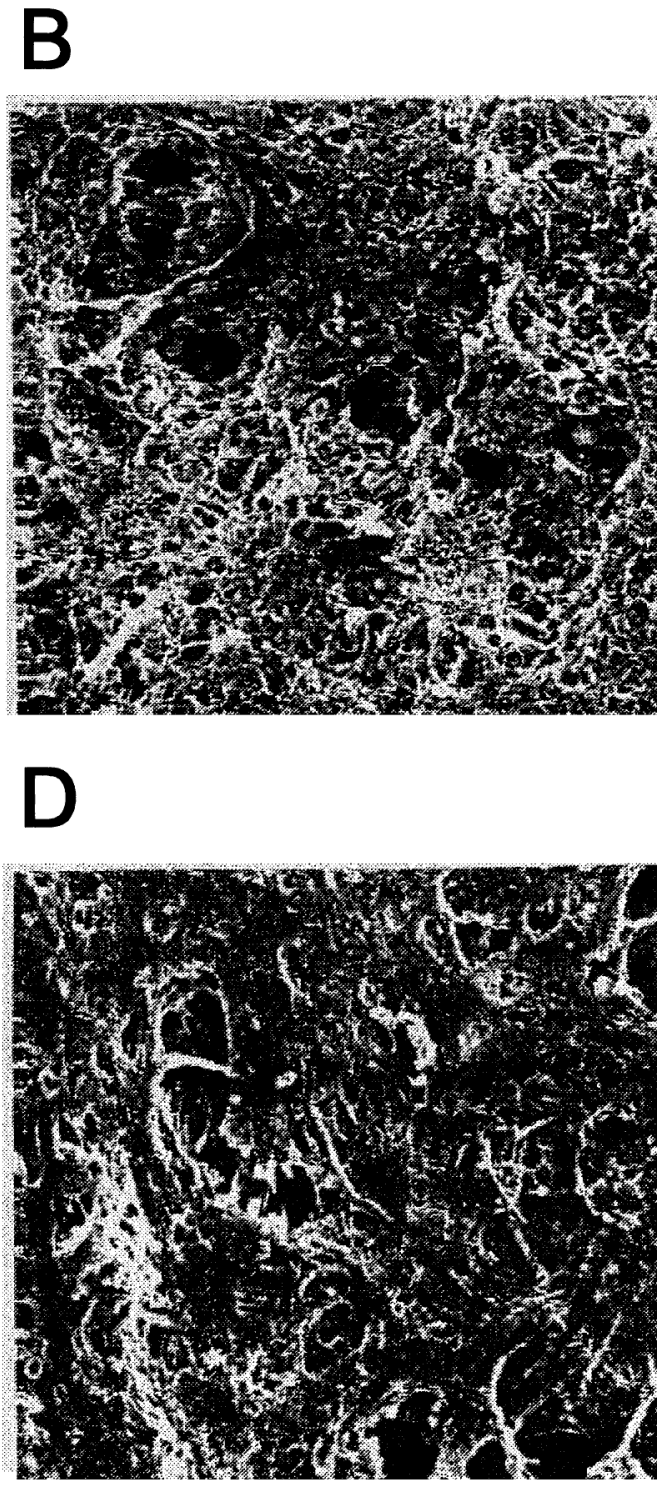

$\overline{50 \mu \mathrm{m}}$

Fig. 7. Scanning electron micrographs of heat-induced gels of porcine myosin (bar length is $50 \mu \mathrm{m})$ : (A-D) gel of extracted myosin on the third day (A), fifth (B), seventh (C) and ninth (D) day of storage. Myosin $(10 \mathrm{mg} / \mathrm{ml})$ in $0.6 \mathrm{M} \mathrm{KCl}$ and $20 \mathrm{~mm}$ phosphate buffer (pH 6.0$)$ was incubated at $60^{\circ} \mathrm{C}$ for $30 \mathrm{~min}$. Gel pieces less than $1 \mathrm{~mm}^{3}$ were fixed in $2.5 \%$ glutaraldehyde in $0.1 \mathrm{M}$ phosphate buffer (pH 7.0 ) for $2 \mathrm{~h}$ at $4{ }^{\circ} \mathrm{C}$. The specimens were then dehydrated using carbon dioxide critical point dryer. Finally, the dehydrated specimens were observed with SEM, at an accelerating voltage of $15 \mathrm{KV}$. 
throughout the matrix were numerous small-sized pores that may cause resistance to applied stress and greater water-holding capacity. On the fifth day of storage, the gel was still dense but was less uniform and not as highly aggregated or interconnected (Fig. 7B). It contained many larger-sized pores not as evenly distributed. On the seventh day of storage, gels became a loose lacy network with obvious decrease in gel strands thickness and the degree of inter-linking between strands (Fig. 7C). The pores became of increased sizes and more irregular. As aging period increased, gel structure seemed to become somewhat discontinuous with less linkage between protein strands and large-sized pores could be observed, as was the case on the ninth day of storage (Fig. 7D).

These obvious physical changes in gel structure during postmortem aging help to explain the functionality differences among the gels, which were expressed by the gradual decrease in their water-holding capacity. It could be concluded that a fine uniform structure with numerous pores would probably result in more absorptive capacity and better retention of water compared to coarse structures with large pores (Hermansson, 1985; Defreitas et al., 1997). Protein denaturation during postmortem aging could account for those physical changes in gels, which disabled them so that they could not firmly retain water. Samejima et al. (1969) pointed out that intact myosin molecule, extracted from rabbit muscle, had been shown to be required for the development of good protein binding properties of heated gels.

In conclusion, porcine myosin is suggested to be unstable during postmortem storage. Taking into account the fact that pork sausages are of high palatability, it could be assumed that denaturation of head during postmortem aging is an important aspect in making sausages. However, prolonged aging may lead to a decrease in the capacity of gels to retain water and consequently affect the quality of the sausages produced. Other than this, there are many factors which are known to be responsible for the physicochemical properties of the heat-induced gel, such as $\mathrm{pH}$, ionic strength, and specific differences between species (Ishioroshi et al., 1983; Lefevre et al., 1998; Wang \& Xiong, 1998). The results revealed in this study would be, in part, informative for the elucidation of properties of the heat-induced gels from pork.

\section{References}

Acton, T.C. and Dick, R.L. (1989). Functional role of heat-induced gelation in processed meat. In "Food Proteins," ed. by J.E. Kinsella and W.G. Soucie. The American Oil Chemist's Society, I.L. Champaign, pp. 195-205.

Alarcon-Rojo, A.D. and Dransfield, E. (1995). Alterations of postmortem aging in beef by the addition of enzyme inhibitors and activators. Meat Sci., 41, 163-178.

Boyer, C., Joandel, S., Ouali, A. and Culioli, J. (1996). Determination of surface hydrophobicity of fast and slow myosins from rabbit skeletal muscles: Implication in heat-induced gelation. J. Sci. Food Agric., 72, 367-375.

Bradford, M. (1976). A rapid and sensitive method for the quantitation of microgram quantities of protein utilizing the principle of proteindye binding. Anal. Biochem., 72, 248-254.

Chan, J.K., Gill, T.A. and Paulson, A.T. (1993). Thermal aggregation of myosin subfragments from cod and herring. J. Food Sci., 58, 1057-1069.

Cofrades, S., Careche, M., Carballo, J. and Jimenez-Colmenero, F. (1997). Thermal gelation of chicken, pork, hake (Merlucciuss merlucciuss L) actomyosin. Meat Sci., 47, 157-166.

Defreitas, Z., Sebranek, J.G., Olson, D.G. and Carr, J.M. (1997). Car- rageenan effects on salt-soluble meat proteins in model systems. $J$. Food Sci., 62, 539-543.

Egelandsdal, B. and Martinsen, B.R. (1994). Myosins from red and white bovine muscles: Differences measured by turbidimetric, calorimetric and rheological techniques. J. Sci. Food Agric., 64, 75-85.

Fujimaki, M., Arakawa, N., Okitani, A. and Takagi, O. (1965). The changes of "myosin B" during storage of rabbit muscle. II. The dissociation of "myosin B" into myosin A and actin, and its interaction with ATP. J. Food Sci., 30, 937-943.

Fukazawa, T., Hashimoto, Y. and Yasui, T. (1961). Effect of storage conditions on physicochemical properties in experimental sausage prepared from fibrils. J. Food Sci., 26, 331-336.

Goody, R.S., Hoffmann, W. and Mannherz, H. (1977). The binding constant of ATP to myosin S-1 fragment. Eur. J. Biochem., 78, 317324.

Grau, R. and Hamm, R. (1956). Die Bestimmung der Wasserbindung des Fleisches mittels der Pre- $\beta$ methode. Fleischwirtschaft, 8, 733 734.

Harrington, W.F. (1979). Contractile proteins of muscle. In "The Proteins," ed. by H. Neuarth and R.L. Hill. Academic Press, New York, pp. 245-409.

Hasselbach, W. and Schneider, G. (1951). Der L-Myosin- und Aktingehalt des Kaninchen-muskels. Biochem Z., 321, 462-475.

Hermansson, A.M. (1985). Water and fat holding. In "Functional Properties of Food Macromolecules," ed. by J.R. Mitchell and D.A. Ledward. Elsevier Applied Science Publishers, London, pp. 273-314.

Ishioroshi, M., Samejima, K. and Yasui, T. (1983). Heat-induced gelation of myosin filaments at a low salt concentration. Agric. Biol. Chem., 47, 2809-2816.

Ishioroshi, M., Samejima, K. and Yasui, T. (1979). Heat-induced gelation of myosin: Factors of $\mathrm{pH}$ and salt concentrations. J. Food Sci., 44, 1280-1284.

Konno, K., Yamamoto, T., Takahashi, M. and Kato, S. (2000). Early structural changes in myosin rod upon heating of carp myofibrils. $J$. Food Chem., 48, 4905-4909.

Laemmli, J. (1970). Cleavage of structural proteins during the cleavage of bacteriophage T4. Nature, 227, 680-685.

Lefevre, F., Fauconneau, B., Ouali, A. and Culioli, J. (1998). Thermal gelation of brown trout myofibrils: Effect of muscle type, heating rate and protein concentration. J. Food Sci., 63, 299-304.

Liu, M.N. and Foegeding, E.A. (1996). Thermally induced gelation of chicken myosin isoforms. J. Agric. Food Chem., 44, 1441-1446.

Lopez-Lacomba, J.L., Guzman, M., Cortijo, M., Maeto, P.L., Aguirre, R., Harvey, S.C. and Cheung, H.C. (1989). Differential scanning calorimetric study of the thermal unfolding of myosin rod, light meromyosin, and subfragment 2. Biopolymers, 28, 2143-2159.

Lowey, S., Slayter, H.S., Weeds, A.G. and Baker, H. (1969). Substructure of the myosin molecule. I. Subfragments of myosin by enzymic degradation. J. Mol. Biol., 42, 1-29.

Macferlane, J.J., Schmidt, G.R. and Turner, R.H. (1977). Binding of meat pieces: A comparison of myosin, actomyosin and sarcoplasmic proteins as binding agents. J. Food Sci., 42, 1603-1605.

Maruyama, K. and Ishikawa, Y. (1963). Effect of magnesium and calcium on the ATPase activity of actomyosin at low ionic strength. Biochim. Biophys. Acta, 77, 682-685.

Morita, J.I., Choe, I.S., Yamamoto, K., Samejima, K. and Yasui, T. (1987). Heat-induced gelation of myosin from leg and breast muscles of chicken. Agric. Biol. Chem., 51, 2895-2900.

Morrissey, P.A., Mulvihill, D.M. and O'Neill, E.M. (1987). Functional properties of muscle protein. In "Development in Food Proteins," ed. by B.J.F. Hudson. Elsevier Applied Science. Ltd, London and New York, pp. 195-256.

Nishimura, T. (1998). Mechanism involved in the improvement of meat taste during postmortem aging. Food Sci. Technol. Int., 4, 241249.

Niwa, E., Kaneohe, S., Nakayama, T., Wattage, S. and Hashimoto, K. (1989). Changes in surface hydrophobicity of fish actomyosin induced by urea. Bull. Jpn. Soc. Sci. Fish., 55, 143-146.

Okumura, T., Inuzuka, Y., Nishimura, T. and Arai, S. (1996). Changes in sensory, physical and chemical properties of vacuum-packed pork loins during the prolonged conditioning at $4^{\circ} \mathrm{C}$. Anim. Sci. Technol., 
67, 360-367.

Park, J.W., Lin, T.M. and Yonngsawatdigul, J. (1997). New developments in manufacturing of surimi and surimi seafood. Food Rev. Int., 13, 577-610.

Parsons, N. and Knight, P. (1990). Origin of variable extraction of myosin from myofibrils treated with salt and pyrophosphate. J. Sci. Food Agric., 51, 71-90.

Privalov, P.L. (1982). Stability of proteins: Proteins which do not present a single cooperative system. Adv. Protein Chem., 35, 351354.

Roussel, H. and Cheftel, J.C. (1990). Mechanisms of gelation of sardine proteins: Influence of thermal processing and of various additives and textures and protein solubility of kamaboko gels. Int. J. Food Technol., 25, 260-280.

Samejima, K., Hashimoto, Y., Yasui, T. and Fukazawa, T. (1969). Heat gelling properties of myosin, actin, actomyosin and myosin subunits in a saline model system. J. Food Sci., 34, 242-245.

Schmidt, R.H. (1981). Gelation and Coagulation. In "Functionality in Foods," ed. by J.P. Cherry. ACS Symposium Series No 147, American Chemical Society, Washington, D.C., pp. 131-148.

Sharp, A. and Offer, G. (1992). The mechanisms of formation of gels from myosin molecules. J. Sci. Food Agric., 58, 63-73.

Sklar, L.A., Hudson, B.S. and Simoni, R.D. (1977). Conjugated polyene fatty acids as membrane probes: Binding to bovine serum albumin. Biochemistry, 16, 5100-5108.

Smyth, A.B., Smyth, D.M. and O'Neill, E. (1998). Disulphide bonds influence the heat-induced gel properties of chicken breast muscle myosin. J. Food Sci., 6, 584-588.

Steen, D., Claeys, E., Uytterhaegen, L., De Smet, S. and Demeyer, D. (1997). Early postmortem conditions and the calpain/calpastatin system in relation to tenderness of double-muscled beef. Meat Sci., 45, 307-319.

Taguchi, T., Ishizaka, M., Tanaka, M., Nagashima, Y. and Amano, K.
(1987). Protein-protein interaction of fish myosin subfragments. $J$. Food Sci., 52, 1103-1104.

Takahashi, K. (1999). Mechanism of meat tenderization during postmortem aging: Calcium theory. 45th ICoMST, Yokohama, pp. 230235.

Visessanguan, W., Ogawa, M., Nakai, S. and An, H. (2000). Physicochemical changes and mechanism of heat-induced gelation of arrowtooth flounder myosin. J. Agric. Food Chem., 48, 1016-1023.

Visessanguan, W. and An, H. (2000). Effects of proteolysis and mechanism of gel weakening in heat-induced gelation of fish myosin. $J$. Agric. Food Chem., 48, 1024-1032.

Wang, B. and Xiong, Y.L. (1998). Evidence of proteolytic activity and its effect on gelation of myofibrillar protein concentrated from bovine cardiac muscle. J. Agric. Food Chem., 46, 3054-3059.

Wang, S.F. and Smith, D.M. (1994). Heat-induced denaturation and properties of chicken breast myosin and F-actin in the presence and absence of pyrophosphate. J. Agric. Food Chem., 42, 2665-2670.

Yasui, T., Ishioroshi, M., Nakano, H. and Samejima, K. (1979). Changes in shear modulus, ultrastructure and spin-spin relaxation times of water associated with heat-induced gelation of myosin. $J$. Food Sci., 44, 1201-1211.

Yasui, T., Ishioroshi, M. and Samejima, K. (1980). Heat-induced gelation of myosin in the presence of actin. J. Food Biochem., 41, 6168.

Yang, R., Okitani, A. and Fujimaki, M. (1970). Postmortem changes in adenosine triphosphatase activity of myofibrils from rabbit muscle. Agric. Biol. Chem., 34, 1765-1772.

Zamorano, J.M. and Gambaruto, M. (1997). Contribution to improving the meat WHC test by the filter paper press method: A comparison of three methods for measuring areas. Meat Sci., 46, 129-137.

Ziegler, G.R. and Foegeding, E.A. (1990). The gelation of proteins. Adv. Food Nut. Res., 34, 203-298. 